\title{
2015 International Society for Disease Surveillance Conference Harnessing Data to Advance Health Equity
}

The International Society for Disease Surveillance (ISDS) will hold its fourteenth annual conference in Denver, CO on December 10th and 11th, 2015. The society's mission is to improve population health by advancing the science and practice of disease surveillance, and the annual conference advances this mission by bringing together practitioners and researchers from multiple fields involved in disease surveillance, including public health, epidemiology, health policy, biostatistics and mathematical modeling, informatics and computer science. This year the conference received 224 abstract submissions, from 20 countries. We accepted 41 abstracts for oral presentations, along with 36 lightning talks and 98 posters.

The last decade has seen our field evolve from a focus on disease surveillance to one on health surveillance. Similarly the traditional emphasis on health disparities has given way to an approach which emphasizes health equity, language which stresses the universal human right to health. Within this framework, surveillance provides the necessary data to advance the health equity agenda. Indeed without these data, we can neither identify where we must do better nor measure our progress towards a more equitable society. With a nod to the tradition and heritage of horses in our host city of Denver, the theme for this year's conference is 'Harnessing Data to Advance Health Equity'.

Our scientific program includes four plenary speakers, each of whom has notable achievements related to the theme of health equity. Ali Mokdad, PhD from the Institute for Health Metrics and Evaluation (IHME) will deliver the opening keynote address. Dr. Mokdad was director of the Behavioral Risk Factor Surveillance System at CDC, and now directs the surveillance and survey work at IHME. He will describe his research on the global burden of disease and the dissemination of data and tools to address challenges facing global health equity. The afternoon of the opening day will feature a plenary talk from Ned Colange, MD, PhD. Dr. Colange was Chief Medical Officer of the Colorado Department of Public Health and Chair of the U.S. Preventive Services Task Force before joining the Colorado Trust as President and CEO. He will speak on his organization's work to achieve health equity for all Coloradans.
Later in the afternoon, we will assemble a panel of three distinguished experts to discuss surveillance, health equity, and human rights. Beth Rivkin, MD, MPH is Director of the Global Health and Justice Project at the University of Washington and will speak on the right to be counted. Vivek Singh, MBBS, MPH is Associate Professor at the Indian Institute of Public Health and coordinator of its Field Epidemiology Training Program; he will speak on polio eradication in India. Ronald St. John, MD, MPH was Director General of the Centre for Emergency Preparedness and Response in Public Health Agency of Canada at the time of the SARS epidemic. He will offer his perspective on surveillance and health equity.

The second day of the conference will begin with a plenary talk by Art Davidson, MD, MPH. Dr. Davidson is Director of Public Health Informatics, Epidemiology and Preparedness at Denver Public Health. He will share perspectives on over two decades of work at the interface of health information technology and public health practice. Our closing keynote speaker will be Anne Marie Kimball, MD, MPH. Dr. Kimball is Senior Consultant at Chatham House, founder of the APEC Emerging Infections Network, a Guggenheim Scholar, and Fellow of the American College of Preventive Medicine. She will speak on emerging threats to health as an issue of equity and the future of surveillance in the $21 \mathrm{st}$ century.

As modern concepts of surveillance continue to evolve, we are excited with the program for the 2015 conference and its focus on health equity. The ISDS brings together professionals from public health practice, industry, health care, and academia. The annual conference is a unique opportunity for this diverse community to gather together, share your knowledge and ideas, and develop a vision for the future of surveillance. We are looking forward to seeing you in Denver!
Al Ozonoff, MA, PhD

Boston Children's Hospital 2015 ISDS Scientific Program Committee Chair 